\title{
Isolation of NDM-1-producing Klebsiella pnemoniae in Ireland, July 2011
}

H McDermott ${ }^{1}$, D Morris ${ }^{2}$, E McArdle ${ }^{3}$, G 0’Mahony ${ }^{1}$, S Kelly $^{1}$, M Cormican², R Cunney (robert.cunney@hse.ie) ${ }^{1}$

1. Department of Clinical Microbiology, Children's University Hospital, Temple Street, Dublin, Ireland

2. Antimicrobial Resistance and Microbial Ecology Group, National University of Ireland, Galway, Ireland

3. Department of Public Health, Health Services Executive, Dr Steeven's Hospital, Dublin, Ireland

Citation style for this article:

McDermott H, Morris D, McArdle E, O’Mahony G, Kelly S, Cormican M, Cunney R. Isolation of NDM-1-producing Klebsiella pnemoniae in Ireland, July 2011.

Euro Surveill. 2012;17(7):pii=20087. Available online: http://www.eurosurveillance.org/ViewArticle.aspx?Articleld=20087

We report the identification of New Delhi metallo-betalactamase 1 (NDM-1)-producing Klebsiella pnemoniae in Ireland. The organism was resistant to multiple antibiotic classes, including carbapenems, and PCR and sequencing confirmed the presence of the $b a_{\mathrm{NDM}-1}$ gene, carried on a $98 \mathrm{~kb}$ plasmid. The organism was isolated from an infant, who was born in India and moved to Ireland at the age of four months. This is the first reported isolation of an NDM-1-producing Enterobacteriaceae strain in Ireland.

\section{Case report}

A six-month old infant presented to the family doctor in May 2011 with a non-specific febrile illness. The child had been born in Kolkata, eastern India, by uncomplicated full-term vaginal delivery. The mother and child spent three to four days in hospital after the birth. The family (two parents and child) moved to Ireland when the child was four months old. The child, who had no underlying illness or past medical history of note, was treated empirically with amoxicillin/clavulanic acid for a suspected urinary tract infection shortly after arrival in Ireland; however, no urine sample was submitted for testing at this time. Six weeks later, the child presented again with a low-grade fever. A urine sample showed a white cell count of $1,700 / \mathrm{mm}^{3}$ and greater than $10^{5}$ bacteria/ml on culture. The isolate was identified as Klebsiella pneumoniae on VITEK 2 (bioMérieux, United States). It was resistant to meropenem (minimum inhibitory concentration (MIC) $>16 \mathrm{mg} / \mathrm{L}$ ), but susceptible to ciprofloxacin. After treatment with a 10-day course of ciprofloxacin, there was a good clinical response. A repeat urine sample after completion of ciprofloxacin therapy grew more than $10^{5}$ bacteria/ml of an isolate identified as Escherichia coli resistant to ciprofloxacin, cefotaxime and cefoxitin but susceptible to ertapenem and trimethoprim. The child received a five-day course of trimethoprim and remains clinically well. A renal ultrasound was normal.

A rectal swab from the child, taken two weeks after the initial positive urine sample, yielded multiple isolates of $K$. pneumoniae including both carbapenem-resistant and carbapenem-susceptible but extended-spectrum cephalosporin-resistant isolates.

The case was investigated by the local Department of Public Health in accordance with international protocols [1]. Family screening for carriage of the NDM1-producing strain was carried out on both urine and rectal samples of the parents. E. coli with a similar susceptibility pattern to the second urinary isolate from the child was isolated from rectal swabs from the parents, but carbapenem-resistant $K$. pneumoniae was not detected.

\section{Laboratory characterisation}

The carbapenem-resistant $K$. pneumoniae isolate from the initial positive urine sample (isolate number 2661) was referred to the Antimicrobial Resistance and Microbial Ecology Group at the National University of Ireland, Galway, for further characterisation. Meropenem and ertapenem MICs were both $>32 \mu \mathrm{g} /$ $\mathrm{ml}$ as determined by Etest. The full susceptibility profile, as determined by the Clinical and Laboratory Standards Institute (CLSI) disk diffusion method [2], is shown in the Table. The isolate was confirmed as a carbapenemase producer by the modified Hodge test of the CLSI, and metallo-beta-lactamase activity was indicated by a commercial synergy test (Rosco Diagnostica, Denmark). PCR and sequencing confirmed the presence of bla $a_{\mathrm{NDM}-1}$, and plasmid analysis revealed this was carried on a $98 \mathrm{~kb}$ plasmid (data not shown) [3,4]. PFGE analysis using $\mathrm{Xbal}$ was carried out on two K. pneumoniae isolates from the child (the carbapenem-resistant $K$. pneumoniae and a carbapenem-sensitive $K$. pneumoniae rectal swab isolate) and on $E$. coli isolated from the child and from both parents [5]. The PFGE profiles of the two $K$. pneumoniae isolates from the child were not similar (data not shown). PFGE profiles of the three $E$. coli isolates were indistinguishable (one from each of the parents and one from the child).

\section{Discussion}

Infections caused by carbapenem-resistant Enterobacteriaceae isolates have been reported in 
hospital outbreaks in Ireland [6], but isolates producing NDM-1 have not previously been identified in Ireland.

Carbapenemase-producing Enterobacteriaceae represent a major threat to current approaches to treatment of life-threatening Enterobacteriaceae infection. In addition to resistance to almost all available betalactam agents, many strains are frequently resistant to multiple classes of antimicrobial agents, including aminoglycosides and fluoroquinolones.

NDM-1-producing $K$. pneumoniae was first recognised in a Swedish patient in $\mathbf{2 0 0 8}$ who was repatriated to Sweden from the Indian subcontinent [7]. Since then, NDM-1-producing isolates have been identified in patients in the United Kingdom who had a history of receiving healthcare in India and Pakistan [8]. The majority of reported clinical cases related to NDM1-producing isolates to date have been in adults. However, NDM-1-producing $E$. coli has recently been reported from rectal screens of neonates returning to France after having attended healthcare facilities in Egypt and India [9]. Two cases of neonatal sepsis associated with NDM-1-positive $K$. pneumoniae have been reported from a neonatal intensive care unit in a tertiary referral hospital in Kolkata, India [10].

The source of colonisation/infection with NDM-1producing $K$. pnemoniae in the child reported here

\section{TABLE}

Susceptibility profile of NDM-1-producing Klebsiella pneumoniae urinary isolate recovered in Ireland, July 2011

\begin{tabular}{|l|l|}
\hline Antibiotic & Susceptibility \\
\hline Chloramphenicol & $\mathrm{S}$ \\
\hline Minocycline & $\mathrm{S}$ \\
\hline Tetracycline & $\mathrm{S}$ \\
\hline Ciprofloxacin & $\mathrm{S}$ \\
\hline Amikacin & $\mathrm{R}$ \\
\hline Kanamycin & $\mathrm{R}$ \\
\hline Ampicillin & $\mathrm{R}$ \\
\hline Ceftazidime & $\mathrm{R}$ \\
\hline Cefotaxime & $\mathrm{R}$ \\
\hline Cefpodoxime & $\mathrm{R}$ \\
\hline Cefoxitin & $\mathrm{R}$ \\
\hline Aztreonam & $\mathrm{R}$ \\
\hline Amoxicillin/clavulanic acid & $\mathrm{R}$ \\
\hline Piperacillin/tazobactam & $\mathrm{R}$ \\
\hline Sulphonamides & $\mathrm{R}$ \\
\hline Streptomycin & $\mathrm{R}$ \\
\hline Gentamicin & $\mathrm{R}$ \\
\hline Nalidixic acid & $\mathrm{R}$ \\
\hline Trimethoprim & $\mathrm{R}$ \\
\hline
\end{tabular}

NDM-1: New Delhi metallo-beta-lactamase 1; R: resistant; S: sensitive.

Susceptibility was determined by the Clinical and Laboratory Standards Institute (CLSI) disk diffusion method [2]. cannot be established unequivocally. However, the fact that the child was born and lived the first few months in India, including a stay of a few days in hospital after birth, is likely to be of relevance given the reported high levels of carbapenemase-producing Enterobacteriaceae in India [11]. Although such organisms were not detected in either parent, a single rectal swab may not identify carriage, particularly if the organism is present in small numbers [12], and the parents may therefore potentially be colonised.

This case highlights the importance of testing isolates from routine clinical samples for susceptibility to carbapenem even in low-incidence areas to maximise the likelihood of detection of carbapenem-resistant Enterobacteriaceae, in order to guide therapy and prevent onward spread through implementation of transmission-based precautions and enhanced environmental cleaning (as was done in this case). Early recognition and reporting in low-incidence areas also provides an opportunity to establish national measures to prevent such isolates becoming endemic in healthcare settings. This report also highlights the importance of considering the possibility of carbapenem-resistant isolates in people returning from the Indian subcontinent.

\section{References}

1. Centers for Disease Control and Prevention (CDC). Guidance for control of infections with carbapenem-resistant or carbapenemase-producing Enterobacteriaceae in acute care facilities. MMWR Morb Mortal Wkly Rep. 2009;58 (10):256-6o.

2. Clinical and Laboratory Standards Institute (CLSI). Performance standards for antimicrobial disk susceptibility tests; approved standard-eleventh edition. Wayne, PA: CLSI; 2012. CLSI document Mo2-A11. Available from: http://www.clsi.org/ source/orders/free/mo2-a11.pdf

3. Nordmann P, Poirel L, Carrër A, Toleman MA, Walsh TR. How to detect NDM-1 producers. J Clin Microbiol. 2011;49(2): 718-21.

4. Barton BM, Harding GP, Zuccarelli AJ. A general method for detecting and sizing large plasmids. Anal Biochem. 1995;226(2):235-40.

5. Swaminathan B, Barrett TJ, Hunter SB, Tauxe RV; CDC PulseNet Task Force. PulseNet: the molecular subtyping network for foodborne bacterial disease surveillance, United States. Emerg Infect Dis. 2001;7:382-9.

6. O'Brien DJ, Wrenn C, Roche C, Rose L, Fenelon C, Flynn A, et al. First isolation and outbreak of OXA-48-producing Klebsiella pneumoniae in an Irish hospital, March to June 2011. Euro Surveill. 2011;16(29):pii=19921. Available from: http://www. eurosurveillance.org/ViewArticle.aspx?Articleld=19921

7. Yong D, Toleman MA, Giske CG, Cho HS, Sundman K, Lee K, et al. Characterization of a new metallo-beta-lactamase gene, bla(NDM-1), and a novel erythromycin esterase gene carried on a unique genetic structure in Klebsiella pneumoniae sequence type 14 from India. Antimicrob Agents Chemother. 2009;53(12):5046-54.

8. Nordmann P, Poirel L, Walsh TR, Livermore DM. The emerging NDM carbapenemases. Trends Microbiol. 2011;19(12):588-95.

9. Birgy A, Doit C, Mariani-Kurkdjian P, Genel N, Faye A, Arlet $G$, et al. Early detection of colonization by VIM-1-producing Klebsiella pneumoniae and NDM-1-producing Escherichia coli in two children returning to France. J Clin Microbiol. 2011;49(8):3085-7.

10. Roy S, Singh AK, Viswanathan R, Nandy RK, Basu S. Transmission of imipenem resistance determinants during the course of an outbreak of NDM-1 Escherichia coli in a sick newborn care unit. J Antimicrob Chemother. 2011;66(12):2773-80.

11. Walsh TR, Weeks J, Livermore DM, Toleman MA. Dissemination of NDM-1 positive bacteria in the New Delhi environment and 
its implications for human health: an environmental point

prevalence study. Lancet Infect Dis. 2011;11(5):355-62.

12. Snyder GM, D’Agata EM. Diagnostic accuracy of surveillance cultures to detect gastrointestinal colonization with multidrugresistant gram-negative bacteria. Am J Infect Control. 2011 Sep 17. [Epub ahead of print]. 